\title{
Activation of amygdala opioid receptors by electroacupuncture of Feng-Chi (GB20) acupoints exacerbates focal epilepsy
}

\author{
Pei-Lu Yi ${ }^{1,2}$, Chin-Yu Lu' ${ }^{1}$, Chiung-Hsiang Cheng ${ }^{1}$, Yi-Fong Tsai ${ }^{1}$, Chung-Tien Lin ${ }^{1 *}$ and Fang-Chia Chang ${ }^{1,3,4^{*}}$
}

\begin{abstract}
Background: The effect of seizure suppression by acupuncture of Feng-Chi (GB20) acupoints has been documented in the ancient Chinese literature, Lingshu Jing (Classic of the Miraculous Pivot), however, there is a lack of scientific evidence to prove it. This current study was designed to elucidate the effect of electroacupuncture (EA) stimulation of bilateral Feng-Chi (GB20) acupoints on the epileptic activity by employing an animal model of focal epilepsy.

Methods: Administration of pilocarpine into the left central nucleus of amygdala (CeA) induced the focal epilepsy in rats. Rats received a 30-min $100 \mathrm{~Hz}$ EA stimulation of bilateral Feng-Chi acupoints per day, beginning at 30 minutes before the dark period and performing in three consecutive days. The broad-spectrum opioid receptor antagonist (naloxone), $\mu$-receptor antagonist (naloxonazine), $\delta$-receptor antagonist (naltrindole) and k-receptor antagonist (nor-binaltorphimine) were administered directly into the CeA to elucidate the involvement of CeA opioid receptors in the EA effect.
\end{abstract}

Results: High-frequency $(100 \mathrm{~Hz})$ EA stimulation of bilateral Feng-Chi acupoints did not suppress the pilocarpine-induced epileptiform electroencephalograms (EEGs), whereas it further increased the duration of epileptiform EEGs. We also observed that epilepsy occurred while $100 \mathrm{~Hz}$ EA stimulation of Feng-Chi acupoints was delivered into naïve rats. EA-induced augmentation of epileptic activity was blocked by microinjection of naloxone, $\mu$ - (naloxonazine), $\mathrm{k}$ - (nor-binaltorphimine) or $\delta$-receptor antagonists (natrindole) into the CeA, suggesting that activation of opioid receptors in the CeA mediates EA-exacerbated epilepsy.

Conclusions: The present study suggests that high-frequency $(100 \mathrm{~Hz})$ EA stimulation of bilateral Feng-Chi acupoints has no effect to protect against pilocarpine-induced focal epilepsy; in contrast, EA further exacerbated focal epilepsy induced by pilocarpine. Opioid receptors in the CeA mediated EA-induced exacerbation of focal epilepsy.

Keywords: Electroacupuncture, Feng-Chi (GB20), Epilepsy, Amygdala, Opioid receptors

\section{Background}

Acupuncture has been used as an alternative medicine to effectively treat patients with chronic pain [1] (e.g., migraines, tension-type headache and peripheral joint osteoarthritis [2]) by manipulating thin needles that have been inserted into the acupoints. Electroacupuncture

\footnotetext{
* Correspondence: ctlin@ntu.edu.tw; fchang@ntu.edu.tw

'Department of Veterinary Medicine, School of Veterinary Medicine, National Taiwan University, No. 1, Sec. 4., Roosevelt Road, Taipei 106, Taiwan

${ }^{3}$ Graduate Institute of Brain \& Mind Sciences, College of Medicine, National

Taiwan University, Taipei, Taiwan

Full list of author information is available at the end of the article
}

(EA) is a modified form of acupuncture, which consists of passing an electrical current through needles into the acupoints and controls the acupuncture dose by modifying the frequency and intensity of stimulating currents. Acupuncture had been documented in some Chinese literatures indicating the therapeutic effect in epilepsy, insomnia, and other neurological diseases, in addition to its indication in pain relief. For example, the effect of epileptic suppression by acupuncture of Feng-Chi (GB20) acupoints has been documented in the Lingshu Jing (Classic of the Miraculous Pivot). However, there is a lack of scientific evidence to elucidate its underlying 
mechanism and to prove the clinical action. Epilepsy is one of the most common and devastating neurological disorders. About seventy percent of patients with epilepsy can be well-controlled with currently available antiepileptic drugs (AEDs), but seizures still persist in $30 \%$ of epilepsy patients who do not respond to any of two to three first-line AEDs despite administration of the carefully optimized drug treatment [3]. Alternative therapies, such as vagus nerve stimulation [4,5], deep brain stimulation (DBS) [6] and acupuncture [7,8], have been considered for treating refractory epilepsy. Several reports demonstrate that acupuncture may suppress seizure activity through the activation of vagus nerve, which subsequently activates the nucleus of tractus solitarius (NTS) $[7,8]$. Our previous results demonstrate that EA stimulation of bilateral Anmian (EX17) acupoints enhances sleep through the activation of opioid receptors in the NTS $[9,10]$. Feng-Chi acupoint is anatomically close to the Anmain acupoint. It has been shown that amygdala receives the afferent projection from the NTS [11,12]. Altering the NTS activity changes dynorphin gene expression in the amygdala [13]. Therefore, stimulation of FengChi acupoints may activate vagus nerve and subsequently modify the opioid receptors in the amygdala to achieve its effect in suppressing focal epilepsy. This study was designed to elucidate the effect of high-frequency $(100 \mathrm{~Hz})$ EA stimulation of Feng-Chi acupoints in an animal model of focal epilepsy by administering pilocarpine into the left central nucleus of amygdala (CeA).

Discovery of endogenous opioid peptides, including $\beta$ endorphin, dynorphin, enkephalin and endomorphin, in the central nervous system (CNS) reveals the mysterious actions of acupuncture, especially in its analgesic effect. It had first been demonstrated that the acupuncture-induced analgesic effect could be blocked by a broad-spectrum opioid receptor antagonist naloxone in both humans and mice $[14,15]$, implicating the role of endogenous opioid peptides. Chang and Pomeranz had revealed that relatively low doses of naloxone only block the analgesic effect induced by lowfrequency $(4 \mathrm{~Hz})$ of electroacupuncture (EA) stimulation, but not the consequence induced by high-frequency $(200 \mathrm{~Hz})$ of EA [16], suggesting that the low-frequency, rather than the high-frequency, of EA increases the release of endogenous opioids. Nevertheless, Han and his colleagues have further shown that the increase of endogenous opioids mediates the analgesic effects induced by both the lowfrequency and high-frequency EA stimuli by employing distinct opioid receptor subtype-specific antagonists $[17,18]$. While $\mu$ - and $\delta$-opioid receptors in the spinal cord are dominant in the low-frequency EA-induced analgesia, K-opioid receptors contribute to the high-frequency EA effects $[17,18]$. Radioimmunoassay of spinal perfusates from rats receiving various frequencies of EA stimulations further indicates that $2 \mathrm{~Hz}$ EA enhances enkephalin (a mixed $\mu$ - and $\delta$-opioid receptor agonist) immunoreactivity (IR), but not the dynorphin ( $\mathrm{k}$ - opioid receptor agonist) IR. In contrast, $100 \mathrm{~Hz}$ EA increases dynorphin IR rather than enkephalin IR [19]. However, whether EA of bilateral FengChi acupoints alters the activity of opioid receptors in the CeA and subsequently changes the epileptic activity in the model of focal epilepsy is not determined. Our current study further elucidated the involvement of CeA opioid receptors in the alteration of epileptic activity induced by high-frequency $(100 \mathrm{~Hz})$ EA stimulation of bilateral FengChi acupoints.

\section{Methods}

\section{Pharmacological agents}

Stock solutions of a broad-spectrum opioid antagonist (naloxone hydrochloride (Tocris, Bristol, UK)), a $\mu$-receptor antagonist (naloxonazine dihydrochloride (Tocris)), a $\delta$-receptor antagonist (naltrindole hydrochloride (Tocris)) and a k-receptor antagonist (nor-binaltorphimine dihydrochloride (Tocris)) were dissolved in pyrogen-free saline (PFS). Pilocarpine $(1 \mathrm{mg} / 1 \mu \mathrm{l})$ was also dissolved in PFS. The stock solutions were stored at $4^{\circ} \mathrm{C}$ until use. Our previous results and others have indicated that the appropriate microinjection dosage for naloxonazine, naltrindole and nor-binaltorphimine to selectively block $\mu-, \delta$ - and $\kappa$-opioid receptors, without interaction with other opioid receptor subtypes, is within $20 \mu \mathrm{g}[9,10,20,21]$. In current study, naloxone, naloxonazine, naltrindole and nor-binaltorphimine were microinjected at the dose of $10 \mu \mathrm{g} / \mu \mathrm{l}$, which efficiently exhibits their effect of pharmacological blockade according to our previous studies $[9,10]$. The total volume used for each microinjection was $1 \mu \mathrm{l}$.

\section{Animals}

Male Sprague-Dawley rats (250 - 300 g; National Laboratory Animal Breeding and Research Center, Taiwan) were used in this study. Rats were anesthetized by intraperitoneal injection with $50 \mathrm{mg} / \mathrm{kg}$ Zoletil $^{\odot}$ (Virbac, Carros, France). Most of rats (groups 2-8, see the experimental protocol) were surgically implanted with three electroencephalogram (EEG) screw electrodes as previously described [22] and a microinjection guide cannulae directed into the left CeA ( $\mathrm{AP}, 2.8 \mathrm{~mm}$ from bregma; ML, $4.2 \mathrm{~mm}$; DV, $7.8 \mathrm{~mm}$ relative to bregma). The coordinates were adopted from the Paxinos and Watson rat atlas [23]. Two screw EEG electrodes were placed over the left frontal and parietal lobes of cortices, and a third EEG electrode was placed over the right cerebellum and served to ground the animal to reduce signal artifacts. Rats in the group 1 were implanted with 6 EEG electrodes; three electrodes were implanted in the left frontal, parietal and occipital lobes and the other three electrodes were implanted in the coordinate right hemisphere. One additional reference electrode was placed over the right 
cerebellum. Insulated leads from EEG electrodes were routed to a Teflon pedestal (Plastics One, Roanoke, VA, USA). The Teflon pedestal was then cemented to the skull with dental acrylic (Tempron, GC Co., Tokyo, Japan). The incision was treated topically with polysporin (polymixin B sulfate - bacitracin zinc) and the animals were allowed to recover for seven days prior to the initiation of experiments. The rats were housed separately in individual recording cages in the isolated room, in which the temperature was maintained at $23 \pm$ $1^{\circ} \mathrm{C}$ and the light:dark (L:D) rhythm was controlled in a 12:12 h cycle (40 Watt $\times 4$ tubes illumination). Food (5001 rodent diet, LabDiet) and water were available $a d$ libitum. All procedures performed in this study were approved by the National Taiwan University Animal Care and Use Committee.

\section{Experimental protocol}

On the $2^{\text {nd }}$ postsurgical day, the rats were connected to the recording apparatus (see below) via a flexible tether. As such, the rats were allowed relatively unrestricted movement within their own cages. One week after rats had adapted to the 12:12-hour L:D cycle after surgery, a 24-hour undisturbed baseline EEG recordings were obtained beginning at dark onset on the $1^{\text {st }}$ recording day in rats from all groups. Nine groups of rats were used in the study as follows. Group $1(n=3)$ was used to determine the focal epilepsy induced by administration of pilocarpine into the left CeA. Rats in the group 2 $(\mathrm{n}=6)$ received a $30-\mathrm{min} 100 \mathrm{~Hz}$ EA stimulation of bilateral Feng-Chi acupoints per day, beginning at $30 \mathrm{mi}-$ nutes before the dark period and performing in three consecutive days (the EA group). EEGs were recorded right after the end of the last period of EA stimuli and lasted for 24 hours. Rats in the group $3(n=6)$ were administered with pilocarpine into the left CeA and EEGs were recorded beginning from the dark onset of the L:D cycle (the pilocarpine group). In the group $4(n=6)$, rats received the same EA stimulation protocol as those rats in the group 2 and were respectively administered with PFS and pilocarpine into the CeA before and after the last period of EA stimulation (the PFS + EA + pilocarpine group). Rats in the group $5(n=6)$ were used to determine the effects of opioid receptor antagonist, naloxone, on the $100 \mathrm{~Hz}$ EA-induced alterations in the epileptiform EEGs (the naloxone + EA + pilocarpine group). Rats in the group $6(n=6), 7(n=6)$, and $8(n=6)$ were respectively used to depict the effects of $\mu$-receptor antagonist (naloxonazine, the naloxonazine $+\mathrm{EA}+$ pilocarpine group), $\delta$-receptor antagonist (naltrindole, the natrindole $+\mathrm{EA}+$ pilocarpine group) and $\mathrm{k}$-receptor antagonist (nor-binaltorphimine, the nor-binaltorphimine + $\mathrm{EA}+$ pilocarpine group) on the $100 \mathrm{~Hz}$ EA-induced alterations of the epileptiform EEGs. Rats in groups 5-8 received the similar protocol as those in the group 4 , except that naloxone $(10 \mu \mathrm{g} / \mu \mathrm{l})$, naloxonazine $(10 \mu \mathrm{g} / \mu \mathrm{l})$, naltrindole $(10 \mu \mathrm{g} / \mu \mathrm{l})$ and nor-binaltorphimine $(10 \mu \mathrm{g} / \mu \mathrm{l})$ were administered into the CeA before the last period of EA stimulation in the group $5,6,7$ and 8, respectively. Rats in the group 9 $(n=6)$ had the similar protocol as those in the group 4, except that rats received the sham EA stimulation (the sham EA group). The schematic representation of the experimental protocol was depicted in Figure 1. When $100 \mathrm{~Hz}$ EA was given (see later), all rats were lightly anesthetized with $29 / 4 \mathrm{mg} / \mathrm{kg}$ of ketamine/xylazine (one third of the dose which we used for surgery in our previous studies $[9,10,22])$, after which rat woke up in 30 to 35 minutes. A 30 -min period of EA stimulation was administered before the onset of the dark period per day and was applied in three consecutive days. The anesthetization was given 30 minutes prior to the dark period onset and lasted for $30 \mathrm{mi}$ nutes. The $100 \mathrm{~Hz}$ EA stimulus was delivered via the bilateral insertion of stainless needles (32 gauge $\times 1$ ", Shanghai Yanglong Medical Articles Co.) on Feng-Chi (GB20) acupoints in the depth of $2 \mathrm{~mm}$. The stimulus consisted of a train of biphasic pulses (150 $\mu$ s duration each) of $100 \mathrm{~Hz}$ with intensity of $1 \mathrm{~mA}$, and was delivered by Functions Electrical Stimulator (Trio 300, I.T.O., Japan). The location of Feng-Chi acupoints in the rat is anatomically similar to that in human. The acupoint of Feng-Chi (GB 20) locates in the depression between the upper portion of $\mathrm{m}$. sternocleidomastoideus and $m$. trapezius in human. Sham EA was performed by stimulation of a non-acupoint located at the ventral conjunction between the forelimb and the trunk as previous described [24].

\section{Apparatus and recording}

Signals from the EEG electrodes were fed into an amplifier (Colbourn Instruments, Lehigh Valley, PA; model V75-01). The EEG was amplified (factor of 5,000) and analog bandpass was filtered between 0.1 and $40 \mathrm{~Hz}$ (frequency response: $\pm 3 \mathrm{~dB}$; filter frequency roll off: $12 \mathrm{~dB}$ /octave). These conditioned EEG signals were subjected to analog-to-digital conversion with 16-bit precision at a sampling rate of $128 \mathrm{~Hz}$ (NI PCI-6033E; National Instruments, Austin, TX). The digitized EEG waveforms were stored as binary computer files pending subsequent analyses. Postacquisition determinations of the onset and the duration of the EEG seizure occurrence were done by the visual scoring using AxoScope 10 Software (Molecular Devices, Sunnyvale, CA, USA). We defined EEG documented seizures as the visualization of epileptiform spikes with amplitudes of greater than $2 \mathrm{mV}$ appearing in discharges lasting for at least 30 seconds [6]. 


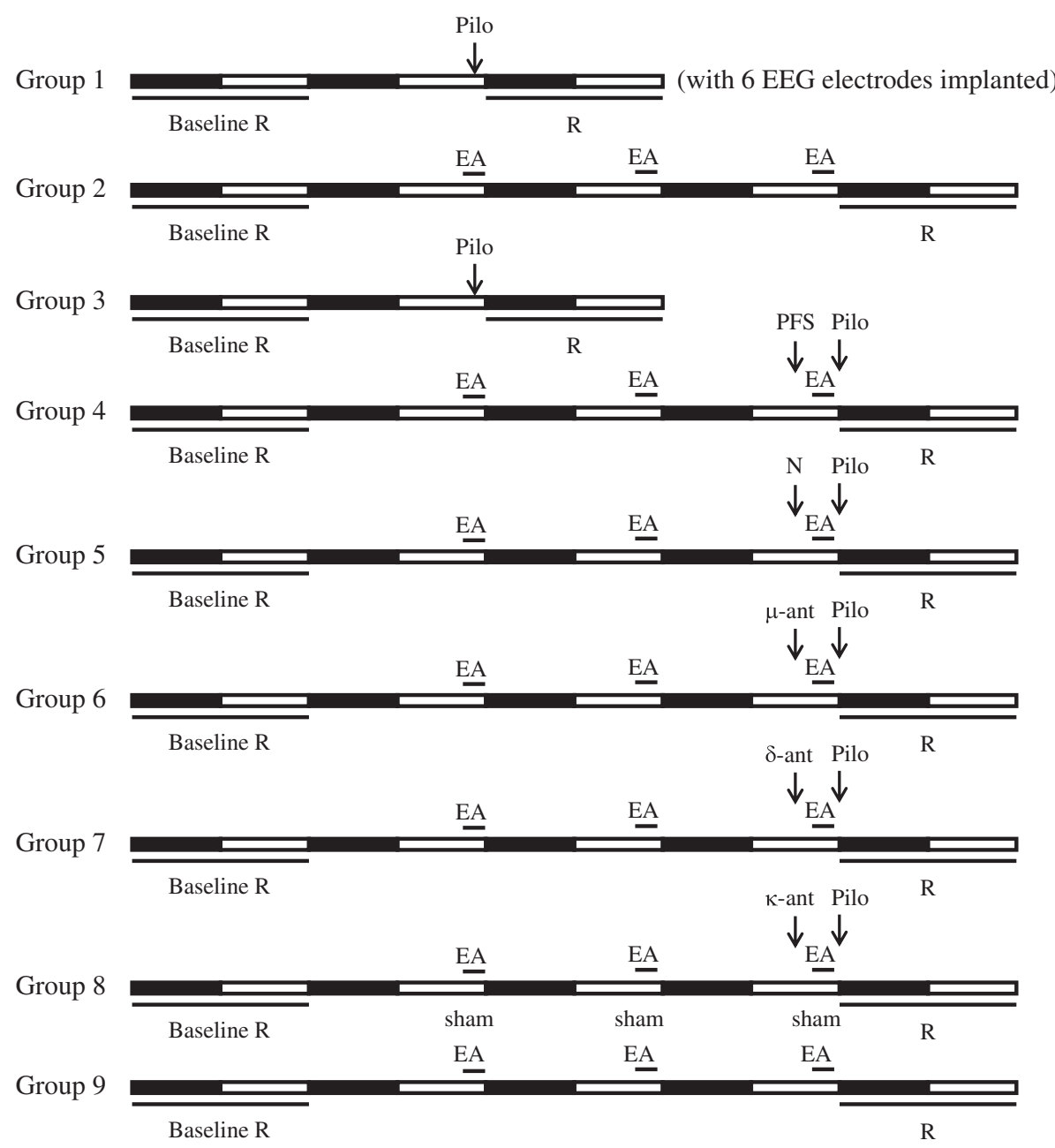

Figure 1 Schematic representation of the experimental protocol. Closed bars indicate the dark period and open bars represent the light period of the 12:12 h light:dark cycle. Arrows depict the time of microinjections. R: EEG recording; Pilo: pilocarpine; EA: electroacupuncture; $\mathrm{N}$ : naloxone; $\mu$-ant: $\mu$-antagonist (naloxonazine); $\delta$-ant: $\delta$-antagonist (naltrindole); K-ant: K-antagonist (nor-binaltorphimine).

\section{Statistical analyses for experiment protocol}

All values acquired from the EEG recordings were presented as the mean \pm SEM for the indicated sample sizes. Unpaired student t-test for the duration of epileptiform EEGs were performed to analyze and compare the difference between groups. An $\alpha$ level of $\mathrm{p}<0.05$ was taken as indicating a statistically significant difference.

\section{Results}

Administration of pilocarpine into the left CeA induces focal epilepsy

The predominant epileptiform EEGs were recorded from the left parietal electrode and some epileptic activities were also acquired from the left occipital electrode when administration of pilocarpine $(1 \mathrm{mg})$ into the CeA in rats of group 1, whereas no epileptic activity was recorded from the rest of four electrodes (Figure 2). The epileptic EEGs were primarily recorded immediately after pilo- carpine injection (Figure 2B \& Figure 3C), and the epileptic recurrence occasionally happened during a day (Figure 3C). The average of time exhibiting epileptiform EEGs in the pilocarpine group (the group 3) was $23.9 \pm$ $5.4 \%$ during the dark period and $20.2 \pm 5.2 \%$ during the following light period (Figure 4A \& 4B). This observation indicates that administration of pilocarpine into the left CeA successfully induces focal epilepsy in rats.

\section{The effect of $100 \mathrm{~Hz}$ EA on pilocarpine-induced focal epilepsy}

We determined the effect of $100 \mathrm{~Hz}$ EA of bilateral Feng-Chi acupoints on the epileptiform EEG activities induced by pilocarpine. There was no epileptic activity been recorded in the naïve rats without any manipulation (Figures 3A, 3E \& 4). We surprisingly found that $100 \mathrm{~Hz}$ EA of bilateral Feng-Chi acupoints induced epileptiform EEGs in four out of six (4/6) naïve rats 


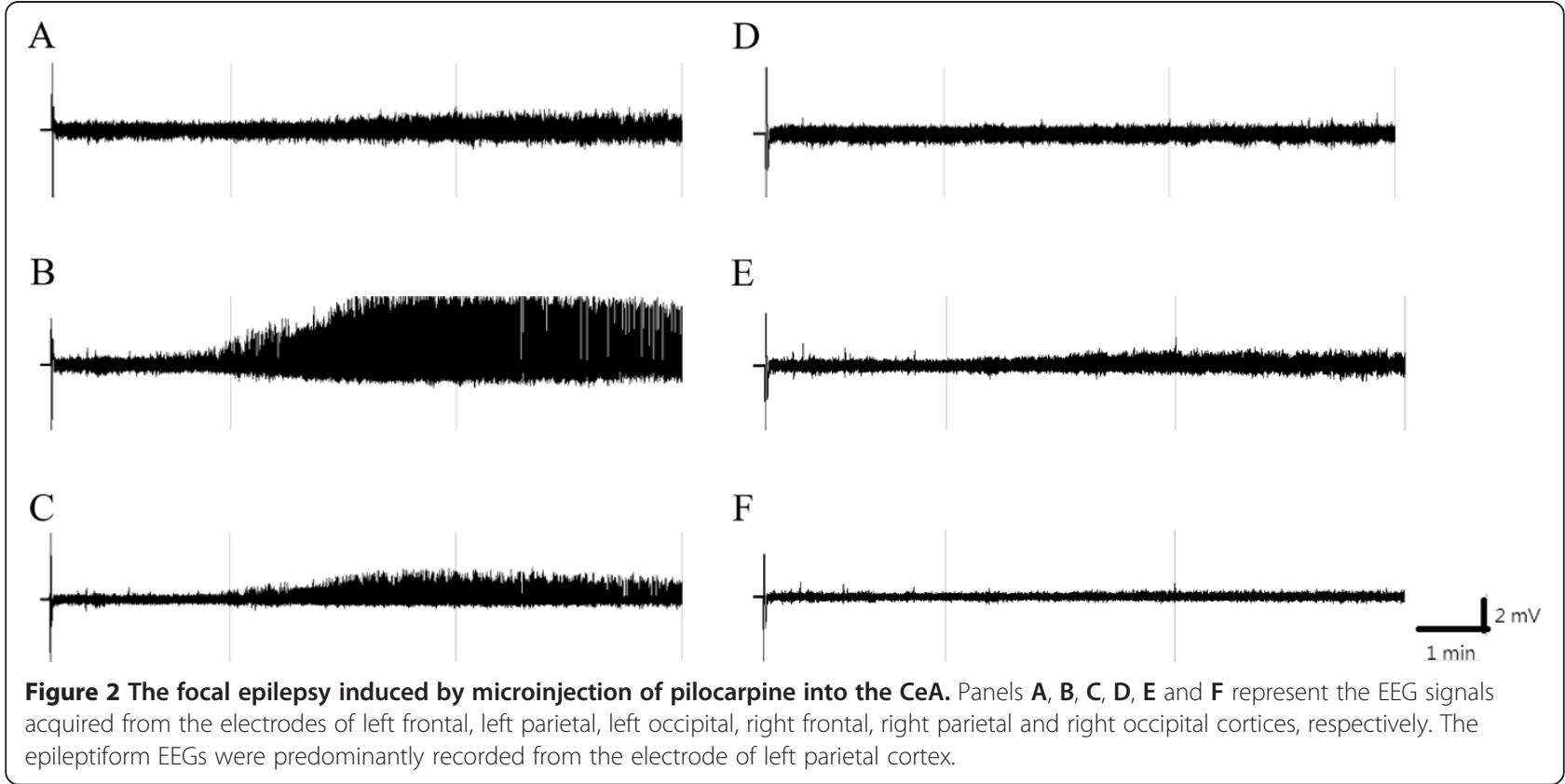

(Figure 3B \& 3F). The average of time exhibiting epileptiform EEGs during the 12 hours of the dark period in the EA group (the group 2) was $2.3 \pm 1.0 \%$, whereas no epileptiform activity was observed in the following light period (Figure 4A \& 4B). The predominant epileptiform EEGs induced by $100 \mathrm{~Hz}$ EA were observed during the first two hours after the EA stimulation (Figure 4C). Furthermore, the high-frequency EA stimulation aggravated the amplitude and duration of the epileptic EEG activity induced by pilocarpine (Figures 3D, 3H \& 4). The average of time presenting epileptic activities in the PFS + EA + pilocarpine group (the group 4) was significantly enhanced to $51.2 \pm 6.1 \%$ during the dark period $(\mathrm{p}<$ 0.01 , when compared to the values obtained from the pilocarpine group) and increased to $57.5 \pm 6.1 \%$ during the following light period $(\mathrm{p}<0.01$, when compared to the results acquired from the pilocarpine group; Figure 4A, 4B \& 4C). Our previous results have shown that sham EA stimulation did not alter baseline EEGs $[9,10]$. We also observed that sham EA stimulation did not exhibit effect on pilocarpine-induced epileptiform EEGs (data not shown).

\section{CeA opioid receptors mediate EA-induced augmentation of focal epilepsy}

Application of naloxone $(10 \mu \mathrm{g})$ significantly reduced the amplitude and duration of EA-induced augmentation of epileptic EEGs (Figure 5B \& 5G). The average of time exhibiting epileptic EEGs in the naloxone + EA + pilocarpine group was significantly reduced to $19.7 \pm 3.5 \%$ during the dark period $(\mathrm{p}<0.01$, when compared to the values obtained from the PFS + EA + pilocarpine group;
Figure 6A) and decreased to $5.0 \pm 1.1 \%$ during the following light period $(\mathrm{p}<0.01$, when compared to the data acquired from the PFS + EA + pilocarpine group; Figure 6B). Both naloxonazine $(10 \mu \mathrm{g})$ and naltrindole $(10 \mu \mathrm{g})$ exhibited similar effect in reducing the amplitude and duration of EA-induced augmentation of epileptic EEGs (Figures 5 \& 6). The average of time presenting epileptic EEGs in the naloxonazine + EA + pilocarpine group and in the naltrindole $+\mathrm{EA}+$ pilocarpine group was respectively decreased to $18.2 \pm 3.8 \%$ ( $\mathrm{p}<$ $0.01)$ and $1.9 \pm 1.1 \%(\mathrm{p}<0.01$, when compared to the values obtained from the PFS + EA + pilocarpine group) during the dark period, and it was decreased to $3.3 \pm$ $1.3 \%(\mathrm{p}<0.01)$ and $0 \%(\mathrm{p}<0.01$, when compared to the data acquired from the PFS + EA + pilocarpine group) during the following light period (Figure 6). Nor-binaltorphimine $(10 \mu \mathrm{g})$ reduced the duration of EA-induced augmentation of epileptic activity, but it exhibited less effect in suppressing the amplitude of epileptiform EEGs (Figure 5E \& 5J). The average of time exhibiting epileptic EEGs in the nor-binaltorphimine + EA + pilocarpine group was significantly reduced to $30.5 \pm 4.7 \%$ during the dark period ( $p<0.01$, when compared to the values obtained from the PFS + EA + pilocarpine group) and decreased to $23.7 \pm 4.0 \%$ during the following light period $(\mathrm{p}<0.01$, when compare to the results acquired from the PFS + EA + pilocarpine group; Figure 6).

\section{Discussion}

The goal of this study is to elucidate the effect of EA stimulation of Feng-Chi acupoints on epileptic suppression. Epilepsy can be divided into focal and generalized 


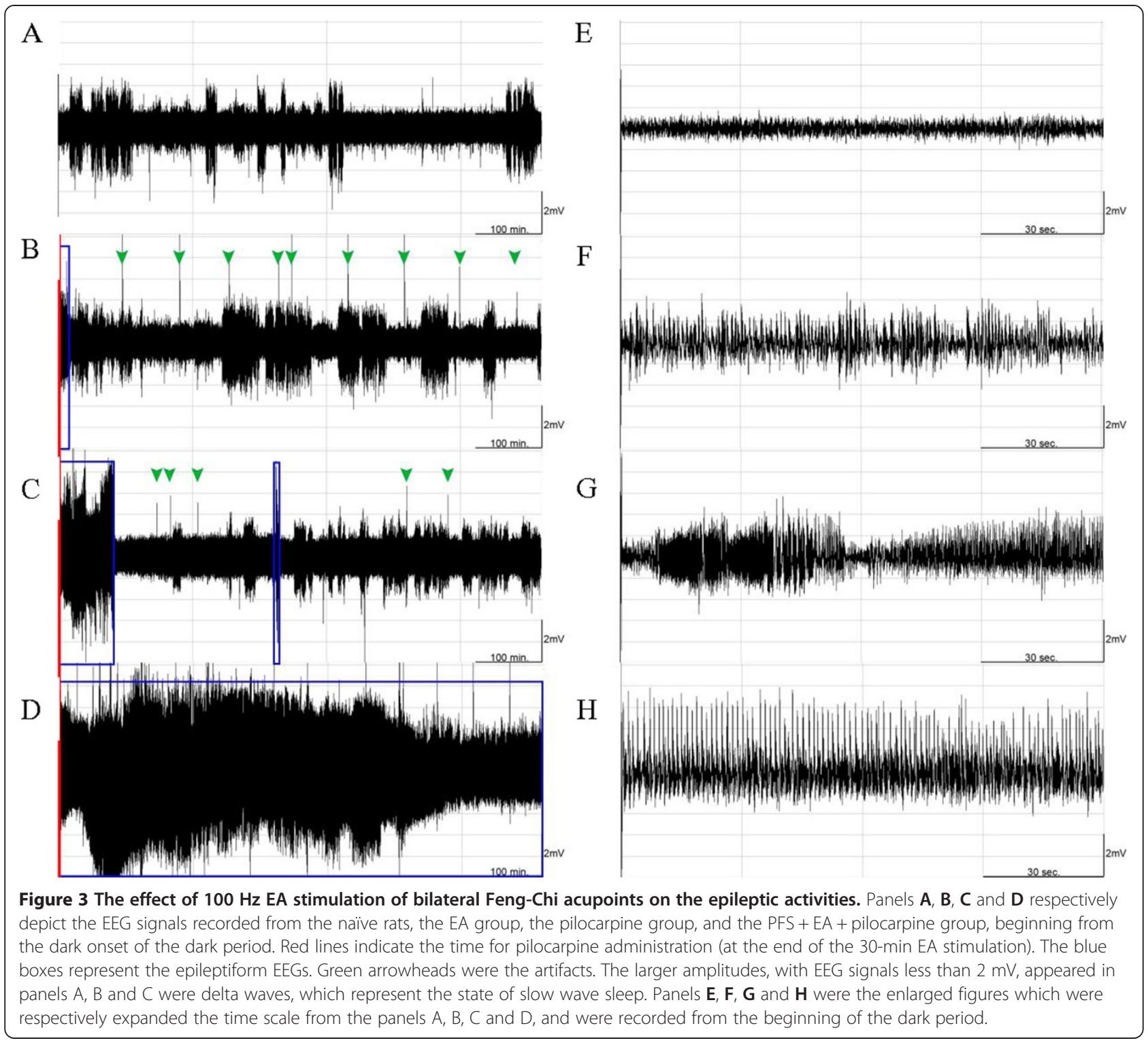

epilepsy according to classification proposed by International League Against Epilepsy (ILAE). Focal epilepsy is usually subtle and the epileptiform activity starts in one area of brain and may spread to other brain regions. In contrast, generalized epilepsy, which is more severe than focal epilepsy, is result of abnormal brain activity in both hemispheres. In this study, we would like to first determine whether EA of Feng-Chi acupoints suppresses focal epilepsy. Systemic administration of pilocarpine in rats leads to a pattern of generalized seizure and status epilepticus [25]. However, the reliability of focal epilepsy induced by administration of pilocarpine into CeA has been confirmed in this study (Figure 2). We found that epileptiform EEGs were primarily recorded from the left parietal electrode near left $\mathrm{CeA}$, but were not acquired from electrodes implanted on the right hemisphere, when EEG signals were acquired by multiple electrodes on both hemispheres.

Acupuncture and EA has been recommended as an alternative medicine for several therapeutic indications by the World Health Organization (WHO), such as alleviation of pain, reduction of inflammation and management of insomnia. The clinical therapeutic effects and the underlying mechanisms of EA in pain relief has been well elucidated; however, its effects in other aspects, such as neurodegenerative diseases, insomnia and epilepsy, has been less investigated. Feng-Chi acupoint (GB 20 ), located in the depression between the upper portion of $\mathrm{m}$. sternocleidomastoideus and $\mathrm{m}$. trapezius in human, has been documented in the Lingshu Jing (the Classic of the Miraculous Pivot) and indicated the therapeutic effects in headache, dizziness, hypertension and epilepsy. 

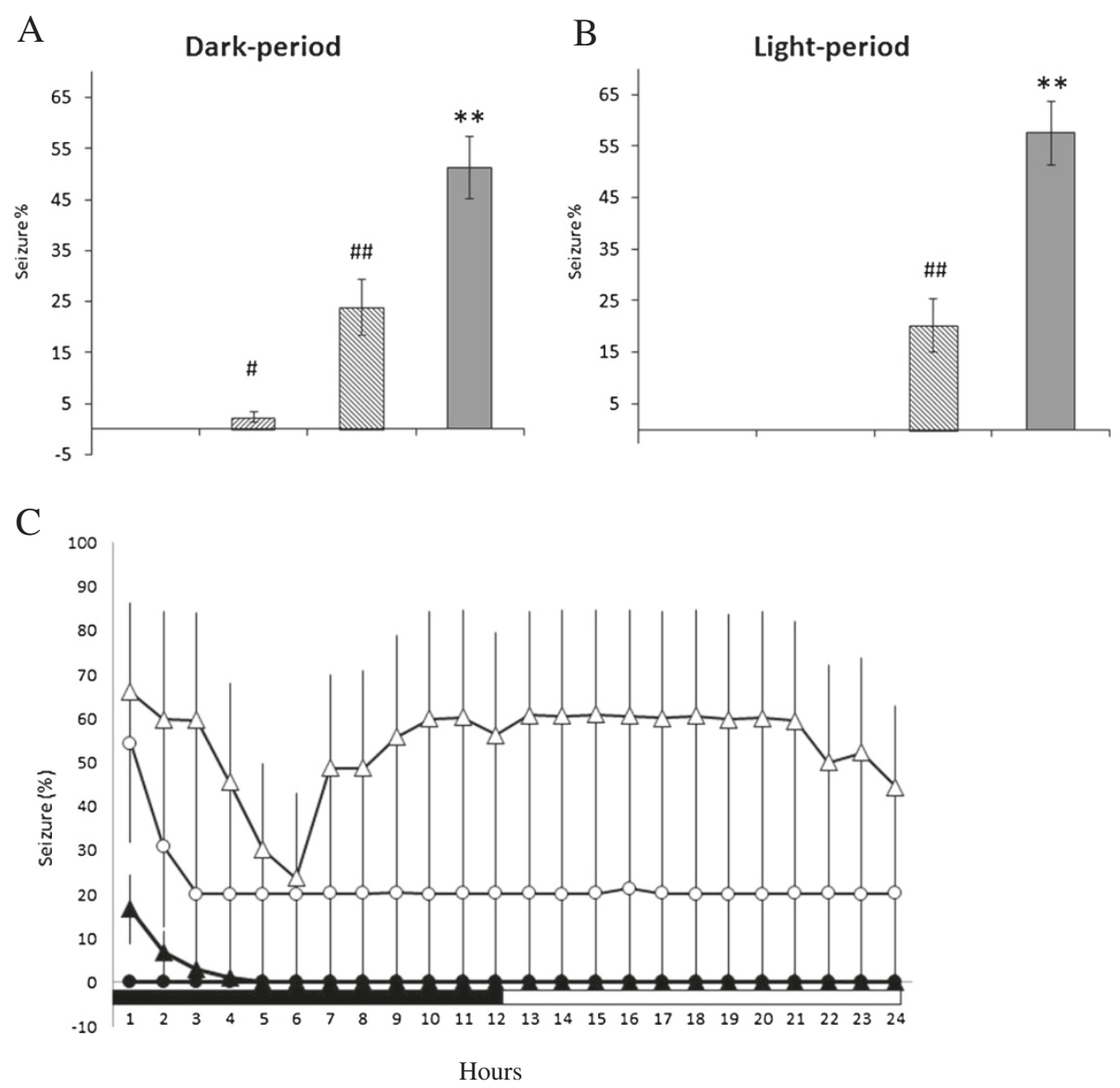

Figure 4 The summary of $100 \mathrm{~Hz}$ EA stimulation of bilateral Feng-Chi acupoints on the epileptic activities. Panel A depicts the results obtained from the dark period and panel $\mathbf{B}$ demonstrates the data acquired from the light period. The bars from the left to the right in both panels $A$ and $B$ represent the results obtained from the naïve rats, the EA group, the pilocarpine group, and the PFS + EA + pilocarpine group. In panel $\mathbf{C}$, the black circles represent the values obtained from the naïve group, the black triangles depict the results of the EA group, the white circles demonstrate the values obtained from the pilocarpine group, and the white triangles indicate the data acquired from the PFS + EA + pilocarpine group. \#: $p<0.05$ vs. the naïve rats; \#\#: $p<0.01$ vs. the naïve rats; ${ }^{* *}: p<0.01$ vs. the pilocarpine group.

Acupuncture may become the alternative choice to treat patients with refractory epilepsy who do not respond to the current AEDs. However, the effect of acupuncture in treating epilepsy is controversial. Activation of vagus nerve by EA has been reported as a promising neuroprotective therapy for patients with refractory epilepsy $[7,8]$. However, bilateral acupuncture of Taichon (LR3), Hegu (LI4) and Baihui (GV20) acupoints did not significantly alter the frequency of seizure occurrence in patients with refractory epilepsy, indicating that acupuncture is not beneficial in patients with refractory epilepsy [26]. A Cochrane review also concludes that no enough scientific evidence supports the effectiveness of acupuncture in epilepsy therapy [27]. To clarify the dispute of acupuncture effect in the epilepsy therapy, we designed this current study to determine the effect of high frequency $(100 \mathrm{~Hz})$ EA of bilateral Feng-Chi acupoints in the focal epilepsy induced by administration of pilocarpine into the left CeA.
Our results indicated that administration of pilocarpine into the left $\mathrm{CeA}$ induced focal epilepsy, however, the pilocarpine-induced epileptiform EEGs were augmented when rats previously received the $100 \mathrm{~Hz}$ EA stimuli of Feng-Chi acupoints. This result indicated that highfrequency $(100 \mathrm{~Hz})$ EA stimulation of bilateral Feng-Chi acupoints exacerbated pilocarpine-induced epileptic activity, rather than protecting against epilepsy. In fact, our data demonstrated that $100 \mathrm{~Hz}$ EA stimulation of bilateral Feng-Chi acupoints induced epileptic activities in the naïve rats, which did not receive any manipulation. The characteristic of epileptogenesis induced by the high-frequency EA stimulation of bilateral Feng-Chi acupoints per se may cause the aggravation of pilocarpineinduced epileptiform EEG activities. These observations, since they subvert the functions of Feng-Chi acupoints documented in the Lingshu Jing, surprise us. The possible reasons of contradiction between our findings and the 


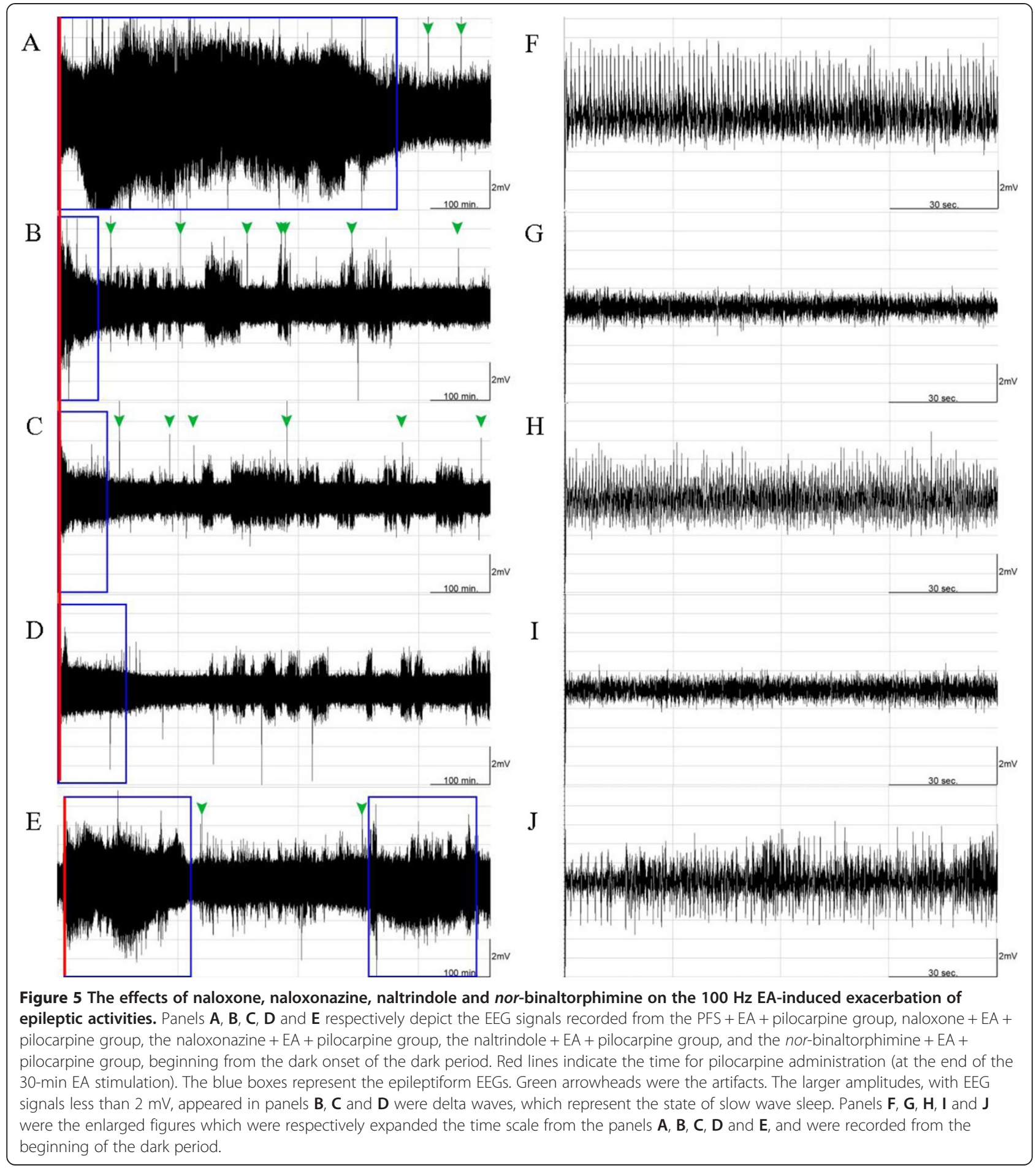

documentation in Lingshu Jing are as follows. First, with or without delivering electrical currents into Feng-Chi acupoints is a fact. The effect of epileptic suppression documented in Lingshu Jing is manipulated by dry needling, whereas the exacerbation of epilepsy we observed in this study was the results after EA with delivering currents into acupoints. Second, different stimulation frequencies may differ the outcomes. It is worthy to investigate the effect of different EA stimulation frequencies, especially for the lower frequency (e.g., $10 \mathrm{~Hz}$ ), on the epileptic activity.

The theory underlying EA is still controversial, although the action of EA has been widely discussed in literature. The discovery of endogenous opioid peptides, including 

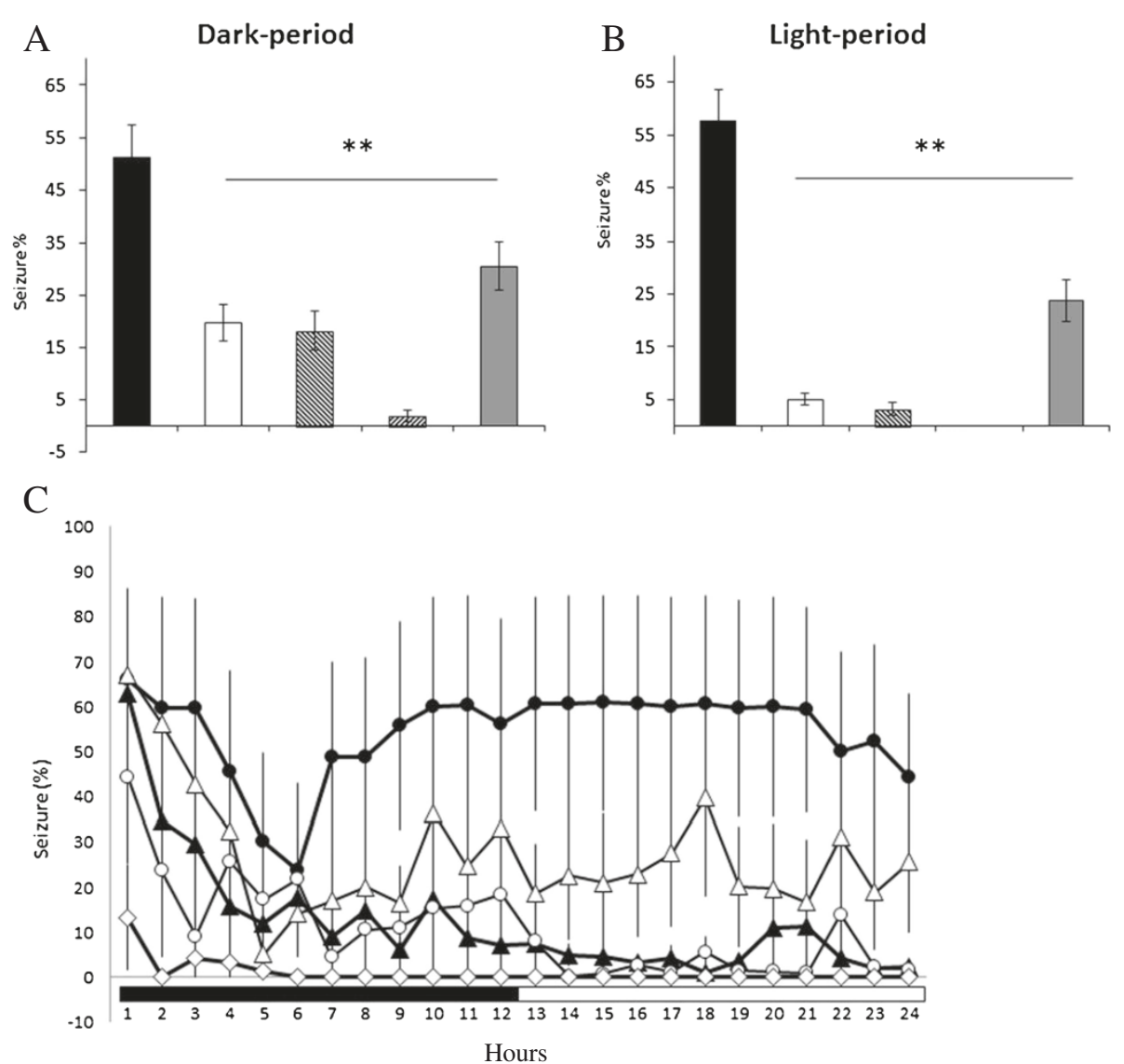

Figure 6 The summary for the effects of naloxone, naloxonazine, naltrindole and nor-binaltorphimine on the $100 \mathrm{~Hz} E A$-induced exacerbation of epileptic activities. Panel A depicts the results obtained from the dark period and panel $\mathbf{B}$ demonstrates the data acquired from the light period. The bars from the left to the right in both panels A and B represent the results obtained from the PFS + EA + pilocarpine group, naloxone $+E A+$ pilocarpine group, naloxonazine $+E A+$ pilocarpine group, naltrindole $+E A+$ pilocarpine group and nor-binaltorphimine + EA + pilocarpine group. In panel C, the black circles represent the values obtained from the PFS + EA + pilocarpine group, the black triangles depict the results of the naloxone $+E A+$ pilocarpine group, the white circles demonstrate the values obtained from the naloxonazine + EA + pilocarpine group, the white diamonds elucidate the results of the naltrindole $+E A+$ pilocarpine group, and the white triangles indicate the data acquired from the nor-binaltorphimine $+E A+$ pilocarpine group. ${ }^{* *}: p<0.01$ vs. the PFS + EA + pilocarpine group.

enkephalin, $\beta$-endorphin, dynorphin and endormorphin, since 1970's enhances the investigation of underlying mechanisms of EA, especially in the EA-induced analgesia. Three main receptor subtypes of the opioid receptors, including the $\mu$-, $\delta$ - and $\kappa$-opioid receptors, in the spinal cord involve in the mechanisms of EA-induced analgesia. Endormorphin and dynorphin are respectively considered as the relatively pure $\mu$ - and $\mathrm{k}$-opioid receptor agonists $[28,29]$, while enkephalin and $\beta$-endorphin are mixed $\mu$ and $\delta$ - opioid receptor agonists (review [30,31]). Han and his colleagues have revealed that low frequency $(2 \mathrm{~Hz}) \mathrm{EA}$ increases met-enkephalin, but not dynorphin, in the spinal cord; while high frequency (100 HZ) EA increases the release of dynorphin rather than that of met-enkephalin [19]. The stimulation of EA between low and high frequency (e.g. $15 \mathrm{~Hz}$ ) activates both enkephalins and dynorphins [19]. They further demonstrated that the analgesic effect induced by low-frequency EA stimulation is mediated by $\mu$ - and/or $\delta$-opioid receptors; in contrast, highfrequency EA-induced analgesia is mediated by к-opioid receptors $[17,18]$. These observations suggest that different endogenous opioid peptides would be released and act on distinct opioid receptors in the spinal cord under different stimulating conditions of EA. It remains unclear whether the endogenous opioid peptides and their receptors in the central nervous system (CNS) play a role in the epileptogenesis or they possess the anticonvulsant effect. Several studies indicate that opioid peptides inhibit the epileptic activity. For example, low doses of morphine or opioid peptides exhibit an anticonvulsant effect, which is blocked by low doses of naloxone [32]. Intracerebroventricular (ICV) administration of dynorphin suppresses the electroconvulsive shock- and kindled-induced seizure [33,34]. Temporal lobe epilepsy increases opioid receptors in the temporal neocortex in humans [35], which may mediate the anticonvulsant effects to limit the spread of electrical 
activity from other temporal lobe structures [34,36]. Furthermore, evidence that the prodynorphin knockout mice display a significantly reduced seizure threshold as assessed by administration of pentylenetetrazole suggests the anticonvulsant effect of endogenous opiates [37]. However, bulks of studies indicate that endogenous opioid peptides and their receptors contribute to the epileptogenesis. ICV injections of morphine and opioid peptides evoke pathological epileptiform EEGs [32,38-42]. $\beta$-endorphin could induce nonconvulsive limbic epileptiform activity in rats when the dose is devoid of analgesic and other behavioral signs [42]. Enkephalin and $\beta$-endorphin administered intracerebroventricularly or microinjected into discrete subcortical areas produce epileptic activities [32]. Repeated injection of small amounts of $\beta$-endorphin or met-enkephalin into the hippocampus or amygdala develops kindled generalized convulsions $[39,40]$. Dynorphin inhibits GABAergic neurons by activation of $\mu$ - and K-opioid receptors, which results in the decrease of GABA release and facilitates seizure [38]. As for the opioid receptors, Carter et al. have demonstrated that opioid receptors are involved in the pathogenesis of a wide spectrum of seizure disorders [43]. Based on aforementioned evidence and our result of exacerbating pilocarpine-induced epileptiform activities by EA stimulation of Feng-Chi acupoints, we hypothesized that the EA-augmented epileptic activity is mediated by activation of opioid receptors in the CeA. Our results indicated that application of naloxone (a broad spectrum of opioid receptor antagonist), naloxonazine (a $\mu$-receptor antagonist), naltrindole (a $\delta$-receptor antagonist) or nor-binaltorphimine (a $\mathrm{k}$-receptor antagonist) significantly suppressed both the amplitude and the duration of EA-induced augmentation of epileptiform activity. The order of efficacy in suppressing EA-induced epileptiform EEGs was naltrindole $>$ naloxone $\cong$ naloxonazine $>$ nor-binaltorphimine. Activation of opioid receptors may mediate the EA-induced epileptic activities in the naïve rats; however, this needs to be further confirmed in the future study. Nevertheless, our current results favor the role of CeA opioid receptors in the epileptogenesis. Han and his colleagues demonstrate that the analgesic effects produced by low-frequency EA stimuli and highfrequency EA stimuli are mediated by different opioid receptors $[17,30]$. Our previous study also elicited that distinct opioid receptors in the NTS involve in different stimulation frequencies of EA-induced sleep enhancement $[9,10]$, which is similar to the underlying mechanisms of EA-induced analgesia in the spinal cord as reported by Han and his colleagues. However, our current results indicate that $100 \mathrm{~Hz}$ EA stimulation of bilateral Feng-Chi acupoints activated $\mu-, \delta$ - and $\mathrm{k}$-opioid receptors in the CeA to exacerbate pilocarpine-induced epilepsy. It is worthy to further investigate the effect of low-frequency (e.g., $10 \mathrm{~Hz}$ ) EA stimulation of bilateral Feng-Chi acupoints on pilocarpine-induced epileptiform activity and the involvement of opioid receptors in the CeA. Strategy by employing pharmacological blockade to elucidate the involvement of particular opioid receptors in $100 \mathrm{~Hz}$ EA-induced augmentation of epileptiform activity is appropriate. However, it would be of interest to mimic the EA-induced epileptiform EEGs by microinjection of opioid-receptor agonists, e.g. $\beta$-endorphin, encephalin and dynorphin, into the CeA in future.

\section{Conclusion}

In summary, our current results indicated that highfrequency $(100 \mathrm{~Hz})$ EA stimulation of bilateral Feng-Chi acupoints exacerbated pilocarpine-induced focal epilepsy. The EA-induced exacerbation of focal epilepsy was blocked by administration of $\mu$-, $\delta$-, or $\kappa$-opioid receptor antagonist into the $\mathrm{CeA}$, demonstrating the involvement of CeA opioid receptors. Our current results suggest that $100 \mathrm{~Hz}$ EA stimulation of bilateral FengChi acupoints did not exhibit effect to against epilepsy, whereas it further deteriorated the focal epilepsy.

\section{Competing interests}

The authors declare that they have no competing interests.

\section{Authors' contributions}

PLY, CYL and YFT carried out the experiments. PLY and CYL analyzed sleep data. PLY, CHC, CTL and FCC designed the experimental protocols. PLY and FCC prepared the manuscript. All authors read and approved the final manuscript.

\section{Acknowledgements}

This work was supported by National Science Council grant NSC99-2320-B002-026-MY3. We thank Mr. Yi-Fong Tsai's technical assistance in this project.

\section{Author details}

${ }^{1}$ Department of Veterinary Medicine, School of Veterinary Medicine, National Taiwan University, No. 1, Sec. 4., Roosevelt Road, Taipei 106, Taiwan.

2Department of Sports, Health \& Leisure, College of Sports Knowledge, Aletheia University, Tainan Campus, Tainan, Taiwan. ${ }^{3}$ Graduate Institute of Brain \& Mind Sciences, College of Medicine, National Taiwan University, Taipei, Taiwan. ${ }^{4}$ Graduate Institute of Acupuncture Science, College of Chinese Medicine, China Medical University, Taichung, Taiwan.

Received: 25 February 2013 Accepted: 25 October 2013

Published: 29 October 2013

\section{References}

1. Vicker AJ, Cronin AM, Maschino AC, Lewith G, MacPherson H, Foster NE, Sherman KJ, Witt CM, Linde K: Acupuncture for chronic pain individual patient data meta-analysis. Arch Intern Med 2012, 172:1444-1453.

2. Lee MS, Ernst E: Acupuncture for pain: an overview of Cochrane reviews. Chin J Integr Med 2011, 17:187-189.

3. Regesta G, Tanganelli P: Clinical aspects and biological bases of drugresistant epilepsies. Epilepsy Res 1999, 34:109-122.

4. DeGiorgio CM, Schachter SC, Handforth A, Salinsky M, Thompson J, Uthman B, Reed R, Collin S, Tecoma E, Morris GL, Vaughn B, Naritoku DK, Henry T, Labar D, Gilmartin R, Labiner D, Osorio I, Ristanovic R, Jones J, Murphy J, Ney G, Wheless J, Lewis P, Heck C: Prospective long-term study of vagus nerve stimulation for the treatment of refractory seizures. Epilepsia 2000 41:1195-1200

5. Woodbury DM, Woodbury JW: Effects of vagal stimulation on experimentally induced seizures in rats. Epilepsia 1990, 31:S7-S19.

6. Jou SB, Kao IF, Yi PL, Chang FC: Electrical stimulation of left anterior thalamic nucleus with high-frequency and low-intensity currents reduces 
the rate of pilocarpine-induced epilepsy in rats. Seizure 2012: doi:10.1016/j.seizure.2012.12.015.

7. He W, Rong PJ, Li L, Ben H, Zhu B, Litscher G: Auricular acupuncture may suppress epileptic seizures via activating the parasympathetic nervous system: a hypothesis based on innovative methods. Evid based Complement Alternat Med 2012, 2012:Article ID 615476

8. Cakmak YO: Epilepsy, electroacupuncture and the nucleus of the solitary tract. Acupunct Med 2006, 24:164-168.

9. Cheng $\mathrm{CH}$, Yi PL, Lin JG, Chang FC: Endogenous opiates in the nucleus tractus solitaries mediate electroacupuncture-induced sleep activities in rats. Evid based Complement Alternat Med 2011, 2011:Article ID159209.

10. Cheng $\mathrm{CH}$, Yi PL, Chang HH, Tsai YF, Chang FC: Kappa-opioid receptors in the caudal nucleus tractus solitarius (NTS) mediate $100 \mathrm{~Hz}$ electroacupuncture-induced sleep activities in rats. Evid based Complement Alternat Med 2012, 2012:Article ID715024.

11. Norgren R: Projections from the nucleus of the solitary tract in the rat. Neuroscience 1978, 3:207-218

12. Ricardo JA, Koh ET: Anatomical evidence of direct projections from the nucleus of the solitary tract to the hypothalamus, amygdala, and other forebrain structures in the rat. Brain Res 1978, 153:1-26.

13. Glass HJ, Briggs JE, Billington CJ, Kotz CM, Levine AS: Opioid receptor blockade in rat nucleus tractus solitarius alters amygdala dynorphin gen expression. Am J Physiol Regul Integr Comp Physiol 2002, 283:R161-R167.

14. Mayer DJ, Price DD, Rafii A: Antagonism of acupuncture analgesia in man by the narcotic antagonist naloxone. Brain Res 1977, 121:368-372.

15. Pomeranz B, Chiu D: Naloxone blocks acupuncture analgesia and causes hyperalgesia: endorphin is implicated. Life Sci 1976, 19:1757-1762.

16. Chang R, Pomeranz B: Electroacupuncture analgesia could be mediated by at least two pain-relieving mechanisms: endorphin and nonendorphin systems. Life Sci 1979, 25:1957-1962.

17. Han JS, Ding XZ, Fan SG: The frequency as the cardinal determinant for electroacupuncture analgesia to be reversed by opioid antagonists. Acta Physiol Sinica 1986, 38:475-482.

18. Chen XH, Han JS: Analgesia induced by electroacupuncture of different frequencies is mediated by different types of opioid receptors: another cross-tolerance study. Behav Brain Res 1992, 47:143-149.

19. Fei H, Xie GX, Han JS: Low and high frequency electroacupuncture stimulation release $\left[\mathrm{Met}^{5}\right]$ enkephalin and dynorphin $\mathrm{A}$ in rat spinal cord. Sci Bull China 1987, 32:1496-1501.

20. Varaschin RK, Morato GS: Selective mu- and kappa-opioid receptor antagonists administered into the nucleus accumbens interfere with rapid tolerance to ethanol in rats. Psychopharmacology (Berl) 2009, 206:85-96.

21. Bodnar RJ, Glass MJ, Ragnauth A, Cooper ML: General, mu and kappa opioid antagonists in the nucleus accumbens alter food intake under deprivation, glucoprivic and palatable conditions. Brain Res 1995, 700:205-212.

22. Chang FC, Opp MR: Blockade of corticotropin-releasing hormone receptors reduces spontaneous waking in the rat. Am J Physiol Regul Integr Comp Physiol 1998, 275:R793-R802.

23. Paxinos $G$, Watson W: The Rat Brain in Stereotaxic Coordinates (4 $4^{\text {th }}$ edition). San Diego: Academic; 1998

24. Yi PL, Tsai CH, Lin JG, Liu HJ, Chang FC: Effects of electroacupuncture at 'Anmian' (extra) acupoints on sleep activities in rats: the implication of the caudal nucleus tractus solitaries. J Biomed Sci 2004, 11:579-590.

25. Jou SB, Kao IF, Yi PL, Chang FC: Electrical stimulation of left anterior thalamic nucleus with high-frequency and low-intensity currents reduces the rate of pilocarpine-induced epilepsy in rats. Seizure 2013, 22:221-229.

26. Kloster R, Larsson PG, Lossius R, Nakken KO, Dahl R, Xiu-Ling X, Wen-Xin Z, Kinge E, Edna R: The effect of acupuncture in chronic intractable epilepsy. Seizure 1999, 8:170-174.

27. Cheuk DKL, Wong V: Acupuncture for epilepsy (review). The Cochrane Collaboration. New Jersey: John Wiley \& Sons; 2006

28. Zadina JE, Hackler L, Ge $\sqcup$, Kastin AJ: A potent and selective endogenous agonist for the $\mu$-opiate receptor. Nature 1997, 386:499-501.

29. Chavkin C, James LF, Goldstein A: Dynorphin is a specific endogenous legend for the k-opioid receptor. Science 1982, 215:413-415.

30. Han JS: Acupuncture and endorphins. Neurosci Lett 2004, 361:258-261.

31. Waldhoer M, Bartlett S, Whistler J: Opioid receptors. Annu Rev Biochem 2004, 73:953-990.
32. Frenk H: Pro- and anticonvulsant actions of morphine and the endogenous opioids: involvement and interactions of multiple opiate and non-opiate systems. Brain Res Rev 1983, 6:197-210.

33. Garant DS, Gale K: Infusion of opiates into substantia nigra protects against maximal electroshock seizures in rats. J Pharmacol Exp Ther 1985 234:45-48.

34. Bonhaus DW, Rigsbee CC, McNamara JO: Intranigral dynorphin-1-13 suppresses kindled seizures by a naloxone insensitive mechanism. Brain Res 1987, 405:358-383.

35. Frost JJ, Mayberg HS, Fisher RS, Douglass KH, Dannals RF, Links JM, Wilson AA, Ravert HT, Rosenbaum AE, Snyder SH, Wagner HN: Mu-opiate receptors measured by positron emission tomography are increased in temporal lobe epilepsy. Ann Neurol 1988, 23:231-237.

36. Madar I, Lesser RP, Krauss G, Zubieta JK, Lever JR, Kinter CM, Ravert HT Musachio JL, Mathews WB, Dannals RF, Frost JJ: Imaging of $\delta$ - and $\mu$-opioid receptors in temporal lobe epilepsy by positron emission tomography. Ann Neurol 1997, 41:358-367.

37. Loacker S, Sayyah M, Wittmann W, Herzog H, Schwarzer C: Endogenous dynorphin in epileptogenesis and epilepsy: anticonvulsant net effect via kappa opioid receptors. Brain 2007, 130:1017-1028.

38. Aradi I, Santhakumar V, Chen K, Soltesz I: Postsynaptic effects of GABAergic synaptic diversity: regulation of neuronal excitability by changes in IPSC variance. Neuropharmacology 2002, 43:511-522.

39. Cain DP, Corcoran ME: Intracerebral $\beta$-endorphin, met-enkephalin and morphine: kindling of seizures and handling-induced potentiation of epileptiform effects. Life Sci 1984, 34:2525-2542.

40. Cain DP, Corcoran ME: Epileptiform effects of met-enkephalin, $\beta$-endorphin and morphine: kindling of generalized seizures and potentiation of epileptiform effects by handling. Brain Res 1985, 338:327-336.

41. Frenk H, Urca G, Liebskind J: Epileptic properties of leucine- and methionine-enkephalin: comparison with morphine and reversibility by naloxone. Brain Res 1978, 147:327-337.

42. Henriksen SJ, Bloom FE, McCoy F, Ling N, Guillemin R: $\beta$-endorphin induces nonconvulsive limbic seizures. Proc Nat Acad Sci USA 1978, 75:5221-5225.

43. Snead OC III, Bearden LJ: The epileptogenic spectrum of opiate agonists. Neuropharmacology 1982, 21:1137-1144.

doi:10.1186/1472-6882-13-290

Cite this article as: Yi et al:: Activation of amygdala opioid receptors by electroacupuncture of Feng-Chi (GB20) acupoints exacerbates focal epilepsy. BMC Complementary and Alternative Medicine 2013 13:290.

\section{Submit your next manuscript to BioMed Central and take full advantage of:}

- Convenient online submission

- Thorough peer review

- No space constraints or color figure charges

- Immediate publication on acceptance

- Inclusion in PubMed, CAS, Scopus and Google Scholar

- Research which is freely available for redistribution 